\title{
Study on the test Performance of Underground XLPE Cables
}

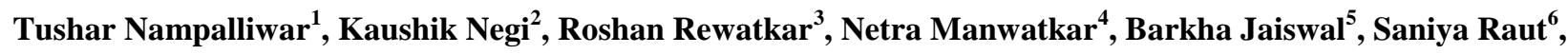 \\ Prof. Diwakar T. Korsane ${ }^{7}$ \\ Students, Electrical Engineering Department, K.D.K. College of Engineering, Nagpur, India ${ }^{1,2,3,4,5,6}$ \\ Asst. Professor, Electrical Engineering Department, K.D.K. College of Engineering, Nagpur, India ${ }^{7}$
}

\begin{abstract}
This paper contributes reports on the phenomena related to degradation of XLPE cables due to various factors. This study focuses on underground XLPE cables which rated at $11 \mathrm{kV}$ for both 1-core and 3-core types. It was shown, that at the highest operating temperature, values of the cable dissipation factor $(\tan \delta)$ significantly increased with ageing. In practice, the cable insulation is subjected to a positive feedback, leading to rise of temperature breakdown risk. Insulation properties changes with time, and it is very necessary that key parameters are tested accurately, to guide on the relative deterioration level of the insulation. The cables are damage due to the adverse installation conditions during cable laying Most of the failures that occur in cable system have a cause that is well known. For instance, failures due to digging activities of other utilities which damages our cable or due to ageing of older components.
\end{abstract}

Keywords: XLPE cable, tan delta, dissipation factor, vlf.

\section{INTRODUCTION}

The Underground XLPE cables are widely used for monitoring. The completed cables are further tested underground cables system especially in urban or compact according to standard testing guidelines before acceptance area that provides many facilities to its community. for use. Furthermore, a joint is a weakest part of an Although underground XLPE cables possess excellent underground cable system owing to the 3 types of stresses dielectric strength, low dielectric permittivity, low loss which are predominant in joint. These are the thermal factor, good dimensional stability, solvent resistance and stress (caused mainly by the externally applied insulation good thermo-mechanical behavior, unfortunately, there are build up and joint encapsulation), electrical stress (caused several weaknesses faced by XLPE cables, which bring down their performance during service.

The damage of XLPE cable is caused by water treeing, electrical treeing and partial discharge and so on. On the other hand, mince of cable causes the aging such as: Thermal, mechanical and electrical stress impacting the electrical insulation. By which, the studying of assessment in XLPE high voltage cable is very interesting and valuable. The studying of leakage current is conducted by the creating of electric circuit simulation in order to understand the relationship characteristic of each failure type in function of applied voltage and frequency that can evaluate the insulation conditions.

Moisture and water absorptions from environment into cable insulation are some important factors that deteriorate cable performance in service and for worse cases; it would cause the cable system to breakdown. From these absorption activities, water treeing phenomena is introduced inside the cable. Insulation and causing the value of tan delta of power cable insulator to increase.

\section{A) WHY CABLES FAIL?}

Power cables are manufactured in factories under controlled environment and sophisticated online mainly due to termination of cable screen in high tension cables) and mechanical stress (as the conductor jointing region is more prone to stress and strain during normal cable loading and development of transient over current during fault conditions superimposed on daily and annual temperature variations). Failures in insulation of cables and accessories are mostly related to ageing and typical basic ageing processes are:

- Thermal breakdown

- Partial discharge

- Electrical treeing

- Water treeing

B) TYPES OF CABLES FAULT

1. Open-circuit fault

2. Short-circuit fault

3. Earth fault.

(i) Open-circuit fault - When there is a break in the conductor of a cable, it is called open circuit fault. The open-circuit fault can be checked by a megger. For this purpose, the three conductors of the 3-core cable at the far end are shorted and earthed. Then resistance between each conductor and earth is measured by a megger. The megger 
will indicate zero resistance in the circuit of the conductor that is not broken. However, if the conductor is broken, the megger will indicate infinite resistance in its circuit.

(ii) Short-circuit fault - When two conductors of a multicore cable come in electrical contact with each other due to insulation failure, it is called a short-circuit fault. Again, we can seek the help of a megger to check this fault. For this purpose, the two terminals of the megger are connected to any two conductors. If the megger gives zero reading, it indicates short circuit fault between these conductors. The same step is repeated for other conductors taking two at a time.

(iii) Earth fault - When the conductor of a cable comes in contact with earth, it is called earth fault or ground fault. To identify this fault, one terminal of the megger is connected to the conductor and the other terminal connected to earth. If the megger indicates zero reading, it means the conductor is earthed. The same procedure is repeated for other conductors of the cable.

\section{PREVIOUS WORK}

Several researchers have tried to correlate insulation dielectric measurements with the service performance of tested cable samples. On the one hand, the dielectric measurements have included Tan $\delta$ at $0.1 \mathrm{~Hz}$ or power frequency, polarization or depolarization currents, and recovery voltage. This paper focuses on the use of Tan $\delta$. On the other hand, the service performance has been characterized by performing a withstand test typically at VLF, or power frequency, or impulse test voltages.

\section{TAN DELTA CONCEPT}

When a sinusoidal voltage is applied across an insulator, the current through the insulator leads the voltage by less than $90^{\circ}$ because of losses in the insulator. If the voltage and current are both sinusoidal, phasor diagram can be depicted as shown in Figure 1. The loss angle $\delta$ is $90^{\circ}-\theta$, where $\theta$ is the phase angle by which the current (I) leads the voltage $(\mathrm{V})$. The loss tangent is $\tan \delta$ and usually values of $\delta$ is very small, with the result that;

$$
\delta(\text { in radians }) \approx \tan \delta \approx \sin \delta=\cos \delta
$$
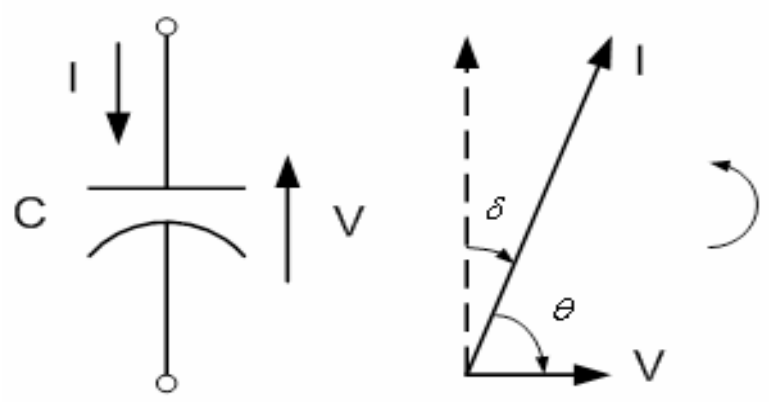

Figure 1: Capacitor and phasor diagram, I (current) lead V (voltage) at $\theta^{0}$ and $\delta$ is loss angle

\section{ASSESSMENT CRITERIA-AGED CABLE SYSTEMS}

The measured values of VLF-TD are primarily influenced by the condition (age, contamination, and moisture ingress) of the various cable system components (accessories, cable insulation, and metallic shield). In addition, some utilities may have components connected to the cable circuit being measured, e.g., oil-filled switches, that cannot be removed but can influence the test results. Most users of dielectric response techniques choose to measure the entire cable system response that would include the responses from all terminations, cable, and joints within the circuit.

Tangent delta measurements provide a global assessment of the dielectric loss. Thus a single region of high loss such as a region of severe water treeing, degraded accessory, area of high moisture or different cable insulation can cause the measured value to rise even though the bulk loss of the majority of the system will be lower. The measured value will be less than the actual loss of the high loss region. A comparison of results between different phases of the same segment or sequential section will help identify if this is the case.

The absolute VLF-TD, the VLF-DTD, and the temporal stability (VLF-TDTS) values are used as figures of merit or compared to historical data to grade the condition of the cable insulation as:

- No action required

- Further study advised, or

- Action required

Table 1-Historical figures of merit for condition assessment of service-aged PE-based insulations (e.g., PE, XLPE, and TRXLPE) using $0.1 \mathrm{~Hz}$

\begin{tabular}{|c|c|c|c|c|c|}
\hline Condition assessment & $\begin{array}{l}\text { VLF-TD Time Stability } \\
\text { measured by standard } \\
\text { deviation at U0, }\left[10^{-3}\right]\end{array}$ & & $\begin{array}{l}\text { Differential VLF-TD } \\
\text { (VLF-DTD) between } 0.5 \\
\text { U0 and } 1.5 \text { U0 }\left[10^{-3}\right]\end{array}$ & & $\begin{array}{c}\text { Mean VLF- } \\
\text { TD at U0 } \\
{\left[10^{-3}\right]}\end{array}$ \\
\hline No Action Required & $<0.1$ & and & $<5$ & and & $<4$ \\
\hline $\begin{array}{c}\text { Further Study } \\
\text { Advised }\end{array}$ & 0.1 to 0.5 & or & 5 to 80 & or & 4 to 50 \\
\hline $\begin{array}{c}\text { Action } \\
\text { Required }\end{array}$ & $>0.5$ & or & $>80$ & or & $>50$ \\
\hline
\end{tabular}


The no action required condition assessment means that, although the cable system can be returned to service, the cable system may be retested at some later date to observe the trend of the tangent delta.

The action required condition assessment means that the cable system has an unusually high set of tangent delta characteristics that may be indicative of poor insulation condition and should be considered for replacement or repair immediately after the test or in the near future. These results may also be used to trigger further testing.

The further study advised condition assessment means that additional information is needed to make an assessment, the additional information could come from previous circuit failure history or additional assessment from an additional diagnostic test; for example, a monitored withstand test can be performed after the VLFTD, VLF-DTD, VLF-TD stability or VLF DS test, the information from the monitored withstand test could be used to enhance the diagnostic and leading eventually to a condition assessment of no action required or action required.

\section{ASSESSMENT CRITERIA-EFFECT OF CABLE LENGTH}

As a tangent delta measurement gives the average value of the dielectric loss for the whole cable circuit tested including the cable and the accessories, it does not give information about how much variation in the loss there is along the cable length. Tangent delta tests can be conducted on cable system lengths from $30 \mathrm{~m}(100 \mathrm{ft})$ to $>3 \mathrm{~km}$ (>10000 ft) with a mean length of $180 \mathrm{~m}(600 \mathrm{ft})$. For example, a short length of cable or an accessory could have a high loss whereas the rest of the circuit has low losses, or severe metallic shield corrosion could affect the tangent delta measurements. One way to overcome this is to compare the tangent delta results with the physical characteristics of the individual circuits, such as the cable length and the number of accessories in the circuit and then plotting the data graphically (tangent delta vs. cable length), preferably on logarithmic scales if there are large variations in the lengths tested or in the tangent delta values measured. Table 2 lists the possible diagnoses based on the slope of the tangent delta vs. cable length curves obtained from extensive measurements.

Table 2-Interpretation of the slopes of the tangent delta vs. cable length plot

\begin{tabular}{|c|c|}
\hline $\begin{array}{c}\text { Slope of tangent delta } \\
\text { vs. length }\end{array}$ & Possible diagnosis \\
\hline $\begin{array}{c}\text { Flat (loss independent } \\
\text { of length) }\end{array}$ & $\begin{array}{c}\text { Uniform loss for all parts of } \\
\text { the cable system }\end{array}$ \\
\hline Random (no clear \\
length dependence) & $\begin{array}{c}\text { No clear pattern of loss. } \\
\text { Each length tested is } \\
\text { different from others in the }\end{array}$ \\
\hline
\end{tabular}

\begin{tabular}{|c|c|}
\hline & $\begin{array}{c}\text { same area. Could be local } \\
\text { variations between lengths }\end{array}$ \\
\hline $\begin{array}{c}\text { Positive slope (loss } \\
\text { increasing with } \\
\text { length) }\end{array}$ & $\begin{array}{c}\text { Corrosion of the metallic } \\
\text { shield or poor contact } \\
\text { between the metallic shield } \\
\text { and the insulation shield. } \\
\text { Isolated loss regions such } \\
\text { as lossy accessories. }\end{array}$ \\
\hline $\begin{array}{c}\text { Negative slope (loss } \\
\text { decreasing with } \\
\text { length) }\end{array}$ & $\begin{array}{c}\text { Isolated loss regions such } \\
\text { as lossy accessories or } \\
\text { heavily water treed regions } \\
\text { within a large proportion of } \\
\text { low loss cable }\end{array}$ \\
\hline
\end{tabular}

\section{ASSESSMENT CRITERIA-NEW CABLE SYSTEMS}

Withstand tests (installation and/or acceptance) on new cable systems can be carried out using the test voltage levels listed in Table 1. The recommended test duration is 60 min. It should also be noted that tangent delta measurements in aged cable systems are sensitive to water tree degradation; whereas, such measurements in acceptance tests on new cable systems are looking for contamination, etc.

As the data available in 2010 from VLF diagnostic tests on the different types of newly installed cable systems are limited, the figures of merit for new cable systems are listed in Table 3. The values given in the tables may change as additional data are accumulated. For new cable systems, the voltage sensitivity of the tangent delta, the differential tangent delta, is expected to be small, as should the temporal stability of tangent delta at constant voltage. The values of VLF-TD are less than 0.012 , below the no action required value given in Table 3 , and the values of VLF-DTD (2U0 - U0) are less than the 0.005 limit given in Table 3.

Table 3 - Criteria for assessment of newly installed cables with PE-based insulations (XLPE and TRXLPE)

\begin{tabular}{|c|c|c|c|c|c|}
\hline $\begin{array}{c}\text { Condition } \\
\text { assessment }\end{array}$ & $\begin{array}{c}\text { Tangent } \\
\text { delta } \\
\text { stability } \\
\text { at U0 } \\
{\left[10^{-3}\right]}\end{array}$ & $\begin{array}{c}\text { Tip up } \\
(2.0 \mathrm{U} 0 \\
- \\
1.0 \mathrm{U} 0) \\
{\left[10^{-3}\right]}\end{array}$ & & $\begin{array}{c}\text { Tangent } \\
\text { delta at } \\
\text { U0 } \\
{\left[10^{-3}\right]}\end{array}$ \\
\hline Acceptable & $<0.1$ & and & $<0.8$ & and & $<1.0$ \\
\hline $\begin{array}{c}\text { Further } \\
\text { study } \\
\text { advised }\end{array}$ & $>0.1$ & or & $>0.8$ & or & $>1.0$ \\
\hline
\end{tabular}

\section{IMPACT OF CABLE AGING ON ITS DISSIPATION FACTOR}

Dielectric spectroscopy in which degraded cables are tested by determining Tan $\delta$ values as a function of frequency $(0.1 \mathrm{~Hz}$ to $10 \mathrm{~Hz})$ as well as a function of voltage has been investigated in several research centers 


\section{International Journal of Innovative Research in Electrical, Electronics, Instrumentation and Control Engineering \\ ISO 3297:2007 Certified \\ Vol. 5, Issue 3, March 2017}

worldwide. In the present investigation this technique was also utilized to examine whether this method could detect water treeing degradation in the third generation cables as well, since some success has been reported in second generation cables which are badly deteriorated due to water treeing. The first generation power polymeric cables were introduced in late 1960s and were equipped with an extruded conductor screen while the insulation screen was of graphite paint or conducting textile tape. These cables were steam cured and manufactured either through tandem or later through $2+1$ extrusion processes. These cables possessed large number of voids and were thus susceptible to water tree degradation. These designs were abandoned in early 1980s when dry extrusion and curing was introduced along with use of cleaner materials.

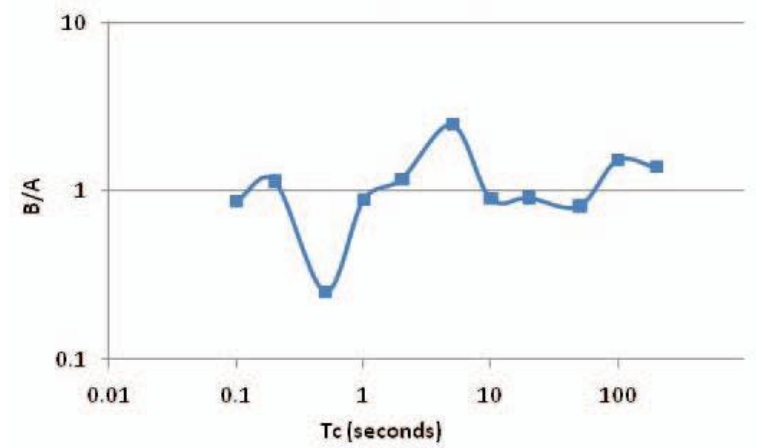

(a)

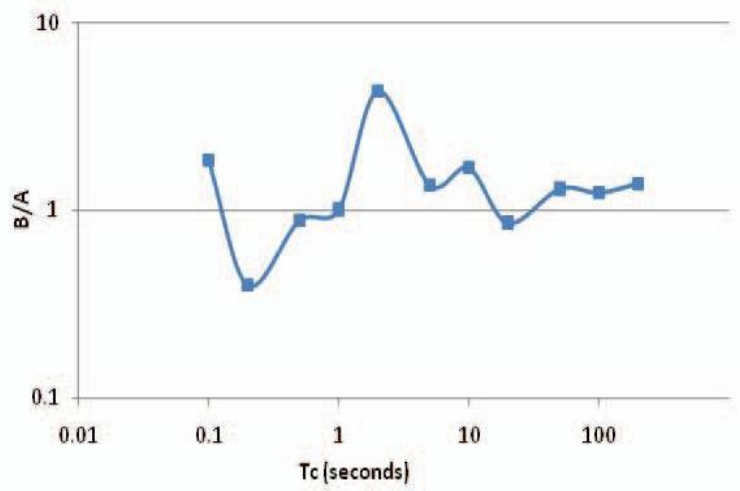

(b)

Figure 2: Division spectra of 3000 hours aged cable measured at $1.0 \mathrm{kV}$ and $2.0 \mathrm{kV}$.

Cables produced so from 1980s up to late 1990s are called second generation cables. These are the cables that are now approaching the end of their service life and therefore are under investigation worldwide for their remaining life. The third generation cables were introduced by using extra clean insulation and semiconducting screen polymers free of trace amounts of impurities and/ or water tight designed XLPE cables. However, water trees occur in all types of polymeric cable designs though to a much lesser extent in the third generation cables. This is why for the third generation cables; the occurrence of low density of water trees makes the cable's condition assessment more difficult.
Past decade has seen lot of efforts being devoted on this technique and as a result several testing standards have been drafted. However, these standards are confined to use of $0.1 \mathrm{~Hz}$ frequency VLF power supplies, since a correlation between an increasing $0.1 \mathrm{~Hz}$ TD and a decreasing insulation breakdown voltage level at power frequency has been reported. According to the TD values at Uo and 2Uo are measured and a differential dissipation factor $\Delta \mathrm{TD}=[\mathrm{TD}(2 \mathrm{Uo})-\mathrm{TD}(\mathrm{Uo})]$ is calculated. The absolute TD and $\Delta \mathrm{TD}$ values are used as figure of merit or compared to historical data to grade the condition of the cable insulation as good, defective, or highly deteriorated. In the present investigation a third generation cable loop $220 \mathrm{~m}$ in length has been subjected to accelerated aging for 3000 hours. Fig. (3) Shows variation of TD in new cable sample as a function of applied voltage at few selected frequencies. The impact of source frequency is also shown. A TD value of $\leq 0.4 \times 10^{-3}$ at $0.1 \mathrm{~Hz}$ for new cable is slightly higher than the reported values for a new $15 \mathrm{kV}$ rated XLPE cable. This could be attributed to the highly resistive stress cones connected on this cable. It is also clear that $0.01 \mathrm{~Hz}$, VLF source exhibits almost an order of magnitude higher TD values as compared to TD values obtained at $0.1 \mathrm{~Hz}-\mathrm{VLF}$.

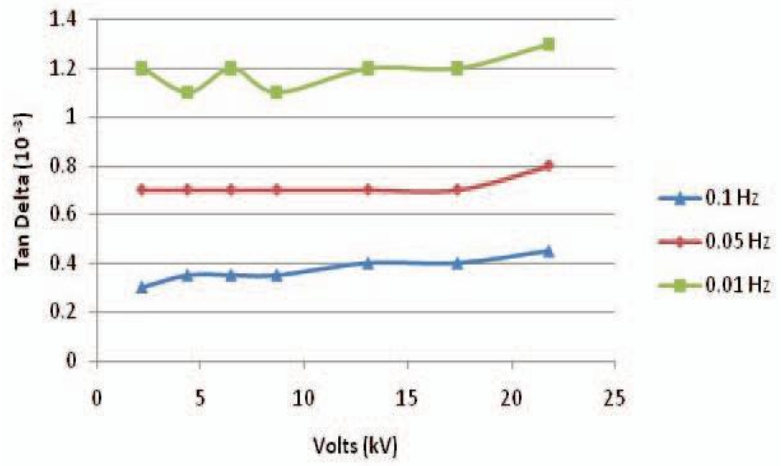

Figure 3: Variation of TD in new XLPE cable.

Table (1) compares the TD values of aged cable in a frequency range of 0.1 to $0.01 \mathrm{~Hz}$ and measured at voltage steps of $0.25 \mathrm{Uo} ; 0.5 \mathrm{Uo} ; 0.75 \mathrm{Uo} ; 1 \mathrm{Uo} ; 1.5 \mathrm{Uo} ; 2 \mathrm{Uo}$ and 2.5 Uo in a systematic manner. It is clear that aging from 2000 hours to 3000 hours has not produced any significant difference in TD values in this cable. According to this procedure, if voltage is applied on water treed cable in steps up to 2.0 Uo and then repeated at lower voltage level of $1.0 \mathrm{Uo}$, indicates a very distinct effect of increase in leakage current which results in higher values of TD at 1.0 Uo that are equal to around the TD values obtained at 2.0 Uo. The occurrence of this phenomenon is indicative of severe water tree degradation of cable. We have tried this procedure on the 3000 hours aged cable but it did not exhibit any such effect and thus shows that this technique may not be successful on mildly deteriorated third generation cable.

Plots of tan delta versus voltage at $0.1 \mathrm{~Hz}$ for circuits containing such accessories will be indistinguishable from 


\section{ISO 3297:2007 Certified}

Vol. 5, Issue 3, March 2017

plots of highly degraded cables. On the other hand, that TD is reduced to $1.9 \times 10^{-3}$. However, an important accessories that geometrically grade the stress do not aspect of these results is that though high permittivity display such effect. In this context, it was shown earlier, accessories installed on XLPE cables exhibit marked that new XLPE cable with a length of 220m exhibited TD effect on TD values measured at $0.1 \mathrm{~Hz}$, but they do not value of around $0.3 \times 10^{-3}$ which is higher than $0.1 \times 10^{-3}$ exhibit such a pronounced effect at $0.01 \mathrm{~Hz}$. This is value reported for the new XLPE cable. To reduce effect certainly another advantage of diagnostic TD of these stress cones, a $55 \mathrm{~m}$ long section of this cable with measurements at $0.01 \mathrm{~Hz}$ instead of $0.1 \mathrm{~Hz}$. However, this only two stress cones on it was subjected to TD interesting phenomena needs to be further explored. measurements. Fig. (4) Illustrates these results. It is clear

Table4. Comparison of TD data collected for 2000 and 3000 Hours of cable aging.

\begin{tabular}{|c|c|c|c|c|c|c|}
\cline { 2 - 6 } \multicolumn{1}{c|}{} & \multicolumn{2}{c|}{$\mathrm{f}=0.1 \mathrm{~Hz}$} & \multicolumn{2}{c|}{$\mathrm{f}=0.05 \mathrm{~Hz}$} & \multicolumn{2}{c|}{$\mathrm{f}=0.01 \mathrm{~Hz}$} \\
\hline Aging Time & \multirow{2}{*}{$2000 \mathrm{hrs}}$. & $3000 \mathrm{hrs}$. & \multirow{2}{*}{$2000 \mathrm{hrs.}$} & \multirow{2}{*}{$3000 \mathrm{hrs}}$. & \multirow{2}{*}{$2000 \mathrm{hrs}}$. & $3000 \mathrm{hrs}$. \\
\hline Applied Voltage (kV)rms & & & & & & \\
\hline 2.2 & $0.3 \times 10^{-3}$ & $0.24 \times 10^{-3}$ & $0.8 \times 10^{-3}$ & $0.8 \times 10^{-3}$ & $1.3 \times 10^{-3}$ & $1.3 \times 10^{-3}$ \\
\hline 4.4 & 0.3 & 0.24 & 0.8 & 0.79 & 1.3 & 1.3 \\
\hline 6.5 & 0.3 & 0.26 & 0.8 & 0.79 & 1.3 & 1.3 \\
\hline 8.7 & 0.3 & 0.27 & 0.8 & 0.81 & 1.3 & 1.3 \\
\hline 13.1 & 0.3 & 0.29 & 0.8 & 0.82 & 1.3 & 1.33 \\
\hline 17.4 & 0.3 & 0.33 & 0.8 & 0.85 & 1.3 & 1.35 \\
\hline 21.8 & 0.3 & 0.34 & 0.8 & 0.87 & 1.4 & 1.43 \\
\hline
\end{tabular}

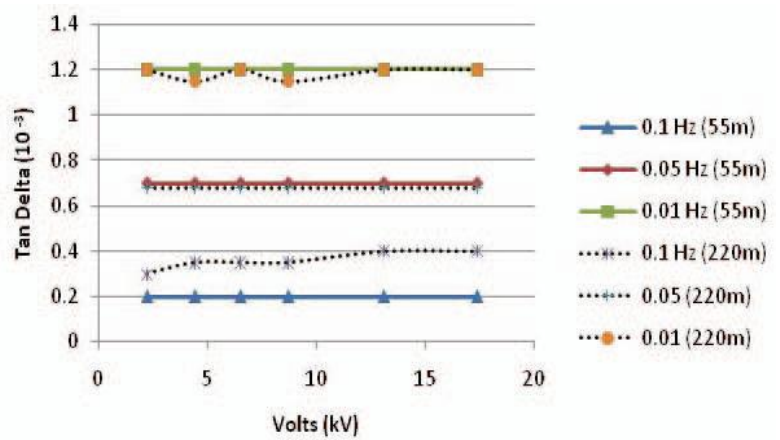

Figure 4: Effect of stress cones on the TD values.

\section{CONCLUSIONS}

After power cables operate for sometimes in service, the value of tan delta is increased. The value of tan delta also increased when the $U$ test voltage is increased. It is because, in most insulating systems, the value of tan delta is intensifying with the increment in applied voltage or stress voltage. However, for unaged cable, the increment of tan delta value against $U$ test voltage is extremely small $(0.0002)$ at $3.5 \mathrm{kV}$ of $\mathrm{U}$ test voltage.

Besides, the capacitance values are not constant when $\mathrm{U}$ test voltage is applied. This situation can be justified that the cables insulation in aging or defect conditions and caused the insulation properties changed. Therefore, it leads the value of cables capacitance versus $U$ test voltage are not constant at the same level. Therefore tan delta and capacitance parameters of XLPE cables insulation are able to evaluate and investigate the quality of underground XLPE cables in service. VLF ac testing uses frequencies of the applied voltage in the range of $0.01 \mathrm{~Hz}$ up to $1 \mathrm{~Hz}$. There are two main wave shapes presently in use, the sinusoidal and cosine-rectangular waveforms. This guide addresses the use of VLF non-monitored (simple) and monitored withstand and other diagnostic field testing of installed shielded power cable systems covering voltage classes from $5 \mathrm{kV}$ up to $69 \mathrm{kV}$. Non-monitored and monitored withstand, tangent delta, differential tangent delta, tangent delta stability, and partial discharge tests at VLF are used as diagnostic tools to assess the condition of cable systems. Tables of test voltage levels are included for installation, acceptance, and maintenance tests on cable systems up to $69 \mathrm{kV}$. Also included are tables giving limits of the temporal stability of tangent delta, differential tangent delta (difference in tangent delta at two test voltages), and absolute values of tangent delta for new and service-aged cable systems.

\section{REFERENCES}

1. R. Sarathi, Supriyo Das, C. Venkataseshaiah and N. Yoshimura (2003). "Investigation of growth of electrical trees in XLPE cable 46 insulation under different voltage profile." Annual Report Conference on electrical Insulation and Dielectric Phenomena. IEEE. 666-669.

2. S. V. Nikolajevic. "Investigation of water effects on degradation of crosslinked polyethylene (XLPE) insulation.” IEEE Transactions on Power Delivery. Volume 8, Issue 4. IEEE. 1993. (1682 - 1688).

3. Nikolajevic, S.V.; Kostoski, D.D. "Accelerated aging of crosslinked polyethylene (XLPE and TR XLPE) cable insulations in wet conditions." Electrical Insulation and Dielectric Phenomena Annual Report. Conference on 25-28 Oct. 1998. (694 - 697 vol. 2).

4. Bahder, G., Katz, C., Eager, G. S., Leber, E., Chalmers, S. M., Jones, W. H., and Mangrum, W. H., "Life Expectancy of Crosslinked Polyethylene Insulated Cables Rated 15 to $35 \mathrm{kV}$," IEEE Transactions PES, vol. 100, pp. 1581-1590, April 1981.

5. Baur, M., "Why should we test power cables with Very Low Frequency?" IEEE Conference ALTAE 2007, Cuernvaca, Mexico.

6. IEEE P400.2 Guide for Field Testing of Shielded Power Cable Systems Using Very Low Frequency. 